\title{
Studies on digestion and absorption in the intestines of growing pigs
}

\section{Measurements of the flow of total lipid, acid-detergent fibre and volatile fatty acids}

\author{
BY I. E. SAMBROOK \\ National Institute for Research in Dairying, Shinfield, Reading RG2 9AT, Berks.
}

(Received I4 February 1979 - Accepted 27 March 1979)

\begin{abstract}
I. Seventeen pigs fitted with single re-entrant cannulas in either the duodenum (posterior to the point of entry of the bile and pancreatic ducts), the mid-jejunum, or the terminal ileum, and a further twenty-four non-cannulated pigs were used.

2. Three diets were used: these contained barley, fine wheat offal, white fish meal, minerals and vitamins (diet BWF); starch, sucrose, maize oil, cellulose, minerals, vitamins and either groundnut meal (diet SSG) or casein (diet SSC).

3. The quantities of total lipid (TL), acid-detergent fibre (ADF) and volatile fatty acids (VFA) passing through the re-entrant cannulas and excreted in the faeces in $24 \mathrm{~h}$ were measured. These were used to determine the net absorption (or synthesis or secretion) in the different regions of the intestine.

4. There was substantial secretion of TL into the proximal small intestine and major absorption from the distal portion for all three diets. In the large intestine there was little or no further net absorption for diets SSG and SSC, but significant synthesis or secretion for diet BWF.

5. Fibre digestion occurred in both the small and large intestines and the apparent absorption of ADF in the different regions studied was influenced by diet.

6. There were detectable amounts of VFA at all sites but only at the ileum and in the faeces could they be accurately measured. Diet did not affect the molar proportions of acetate, propionate and butyrate in ileal digesta, but did have an effect on these VFA in the faeces.
\end{abstract}

There has been increasing emphasis on the use of animals fitted with intestinal re-entrant cannulas to study the processes of digestion and absorption in farm livestock with a view to improving foodstuff utilization. Sambrook (1979) reported on the flow of some of the major carbohydrate fractions; this paper discusses the flow of acid-detergent fibre (ADF) and the volatile fatty acids (VFA) resulting from its bacterial degradation, and of total lipid (TL).

\section{EXPERIMENTAL}

Animals and animal management. This was as described by Sambrook (1979).

Diets. Diets BWF, SSG and SSC (for details, see Table I) contained respectively $(\mathrm{g} / \mathrm{kg})$ : TL $40 \cdot 8,39.8$ and 30.7 ; ADF $68 \cdot 6,96.5$ and $29 \cdot 7$. Because initially there were frequent blockages of ileal re-entrant cannulas when diet BWF was fed, this diet was finely milled through a I $\mathrm{mm}$ mesh before being fed to pigs with ileal re-entrant cannulas in subsequent collections. The finely-milled diet (designated $\mathrm{BWF}_{\mathrm{f}}$ ) was also fed to six of the pigs in the digestibility trial.

The experimental diet was mixed with water $(\mathrm{I}: 2 \cdot 5, \mathrm{w} / \mathrm{v})$ immediately before feeding and offered twice daily at 09.00 and 15.00 hours. The pigs were weighed each week and fed according to a scale based on live weight (Barber et al. 1972). Pigs of $20 \mathrm{~kg}$ live weight received $\mathrm{I} .05 \mathrm{~kg}$ diet $/ \mathrm{d}$ and the amount increased linearly so that at $60 \mathrm{~kg}$ live weight the pigs received $2.40 \mathrm{~kg}$ diet $/ \mathrm{d}$.

$T L$ determination. Approximately $\mathrm{I} g$ freeze-dried material from a pooled sample representative of each $24 \mathrm{~h}$ collection was extracted for $6 \mathrm{~h}$ using approximately $200 \mathrm{ml}$ 
Table I. Composition of experimental diets $(\mathrm{g} / \mathrm{kg}$ diet $)$

\begin{tabular}{|c|c|c|c|c|}
\hline Ingredients & $\begin{array}{l}\text { Diets } B W F \\
\text { and } B W F_{1}^{*}\end{array}$ & Ingredients & Diet SSG & Diet SSC \\
\hline $\begin{array}{l}\text { Barley meal } \\
\text { Fine wheat offal }\end{array}$ & $\begin{array}{l}712 \cdot 5 \\
200 \cdot 0\end{array}$ & $\begin{array}{l}\text { Maize starch } \\
\text { Sucrose }\end{array}$ & $\begin{array}{l}277 \cdot 0 \\
276 \cdot 9\end{array}$ & $\begin{array}{l}612 \cdot 7 \\
100 \cdot 0\end{array}$ \\
\hline White fish meal & $70 \cdot 0$ & Maize oil & $\begin{array}{r}270.9 \\
30.0\end{array}$ & $\begin{array}{r}100.0 \\
30.0\end{array}$ \\
\hline $\mathrm{NaCl}$ & $2 \cdot 7$ & Solka flocł & $20 \cdot 0$ & 30.0 \\
\hline $\mathrm{CaHPO}_{4} .2 \mathrm{H}_{2} \mathrm{O}$ & $5 \cdot 6$ & Groundnut meal & $350 \cdot 0$ & - \\
\hline $\mathrm{CaCO}_{3}$ & $6 \cdot 2$ & Casein & - & $184 \cdot 0$ \\
\hline Vitamin mix no. i & $2 \cdot 0$ & Trace mineral mix§ & $10 \cdot 0$ & $10 \cdot 0$ \\
\hline \multirow[t]{7}{*}{$\mathrm{CuSO}_{4} \cdot 5 \mathrm{H}_{2} \mathrm{O}$} & I.O & $\mathrm{CaHPO}_{4} \cdot 2 \mathrm{H}_{2} \mathrm{O}$ & 17.9 & $20 \cdot 6$ \\
\hline & & $\mathrm{CaCO}_{\mathrm{g}}$ & $4 \cdot 6$ & $4 \cdot 6$ \\
\hline & & Vitamin mix no. 2\|l. & $2 \cdot 0$ & $2 \cdot 0$ \\
\hline & & Choline hydrochloride & $1 \cdot 1$ & $I \cdot I$ \\
\hline & & $\mathrm{NaCl}$ & 5.0 & $5 \cdot 0$ \\
\hline & & L-lysine hydrochloride & $2 \cdot 5$ & - \\
\hline & & DL-methionine hydrochloride & 3.0 & - \\
\hline
\end{tabular}

* Diet BWF after milling through a I mm mesh; this diet was given to pigs with ileal re-entrant cannulas and to some pigs in the digestibility trial.

† Supplied (/kg diet): $0.75 \mathrm{mg}$ retinol, $7.50 \mu \mathrm{g}$ cholecalciferol, $3.25 \mathrm{mg}$ riboflavin, $30.00 \mu \mathrm{g}$ cyanocobalamin, $15.75 \mathrm{mg}$ nicotinic acid, $13.00 \mathrm{mg}$ pantothenic acid, $3.25 \mathrm{mg}$ pyridoxine, $200.00 \mathrm{mg}$ choline chloride, 2.00 $\mathrm{mg}$ DL- $\alpha$-tocopheryl acetate.

$\ddagger$ Brown and Co., Berlin, New Hampshire, USA.

$\S$ Supplied (/kg diet): $4.47 \mathrm{~g} \mathrm{~K} \mathrm{CO}_{3}, 1 \cdot 73 \mathrm{~g} \mathrm{MgCO}_{3} . \mathrm{H}_{2} \mathrm{O}, 0.33 \mathrm{~g} \mathrm{FeSO}_{4} \cdot 7 \mathrm{H}_{2} \mathrm{O}, 60 \mathrm{mg} \mathrm{MnSO}, \cdot \mathrm{H}_{2} \mathrm{O}$, $0.10 \mathrm{~g} \mathrm{ZnCO}, 8.00 \mathrm{mg} \mathrm{NaF}, 17.50 \mathrm{mg} \mathrm{CuSO} \mathrm{H}_{4} .5 \mathrm{H}_{2} \mathrm{O}, 6.00 \mathrm{mg} \mathrm{CoCl}$.

II Supplied ( $/ \mathrm{kg} \mathrm{diet}$ ): as vitamin mix no. I (omitting choline chloride) and in addition $2.00 \mathrm{mg}$ thiamin, $50.00 \mu \mathrm{g}$ biotin, $0.50 \mathrm{mg}$ pteroylmonoglutamic acid, $20.00 \mathrm{mg} \rho$-aminobenzoic acid, $194.00 \mathrm{mg}$ myo-inositol, $30.00 \mathrm{mg}$ ascorbic acid, $2.00 \mathrm{mg}$ menaphthone.

chloroform-methanol $(2: 1, \mathrm{v} / \mathrm{v})$ in a Soxhlet apparatus. The extract was made up to $250 \mathrm{ml}$ with chloroform-methanol $(2: \mathrm{I}, \mathrm{v} / \mathrm{v})$ and washed with $50 \mathrm{ml}$ potassium chloride solution $(8.8 \mathrm{~g} / 1)$ (Folch et al. 1957). The two phases were allowed to separate completely (usually overnight), then the solvent phase was drained off and evaporated to dryness under nitrogen. Samples were alternately heated in an oven at $100^{\circ}$ and dried under $\mathrm{N}_{2}$ until constant weight was reached.

$A D F$ determination. Approximately I $g$ finely-ground freeze-dried material from a pooled sample representative of each $24 \mathrm{~h}$ collection was refluxed for $\mathrm{I} \mathrm{h}$ with $100 \mathrm{ml}$ cetyltrimethylammonium bromide in I M-sulphuric acid $(20 \mathrm{~g} / \mathrm{l})$ (Van Soest, $1973 b)$. This method measures the lignin and cellulose content of the sample. The residue after filtration was washed and dried under vacuum. The ADF content was determined by difference after incinerating the residue at $500^{\circ}$ overnight to leave only the ash.

$V F A$ determination. For faecal samples, $0.5 \mathrm{~g}$ freeze-dried material was extracted with

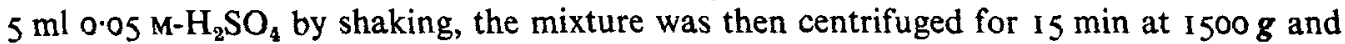
the supernatant fraction decanted. For digesta samples, the supernatant fraction obtained by centrifuging a $24 \mathrm{~h}$ pooled sample representative of each $24 \mathrm{~h}$ collection for $15 \mathrm{~min}$ at I $500 \mathrm{~g}$ was used. A $3 \mathrm{ml}$ sample of the supernatant fraction was treated with $0.6 \mathrm{ml} \mathrm{meta-}$ phosphoric acid, and a fixed volume $(0.6-0.7 \mathrm{ml}) n$-pentanol was added to each as an internal reference compound. The VFA were analysed on a Pye 106 Chromatograph (Pye Unicam) with a flame-ionization detector, using isothermal runs.

Presentation of results. The quantities of TL and ADF are expressed as the ratio, weight collected in $24 \mathrm{~h}$ : weight ingested in diet and water in $24 \mathrm{~h}$ (output:intake; O:I) to indicate the net result of absorption and secretion in each region of the gut studied.

The amounts of VFA detected in the digesta at the duodenum and jejunum were generally 
Table 2. Mean 24 h output: intake for total lipid in pigs given different diets (a) for digesta collected from pigs with intestinal re-entrant cannulas at one of three sites, $(b)$ for faeces collected from pigs without cannulas

(No. of pigs completing collections given in parentheses)

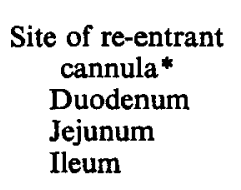

(a) Cannulated pigs

SE of difference between site means: least value 0.119 , greatest value 0.206 . SE of difference between diet means: least value 0.036 , greatest value 0.198 .

(b) Pigs without cannulas (six pigs/diet)

$\begin{array}{ccccc} & \text { Diet BWF } & \text { Diet BWF } & \text { Diet SSG } & \text { Diet SSC } \\ \text { Faeces } & 0.42 & 0.33 & 0.20 & 0.07\end{array}$

SE of difference between diet means: 0.022 .

$S E$ of difference between means for faeces and ileum: least value 0.021 , greatest value 0.030 .

* For details of sites, see p. 279.

† Diet BWF was finely milled (diet $\mathrm{BWF}_{\mathrm{s}}$ ) when fed to pigs with ileal cannulas; for details of diets see p. 279 and Table 1.

too low to be measured accurately so only the results for ileal digesta and faeces are presented. The VFA content of the digesta is in constant flux as absorption by the pig and production by bacterial action on dietary fibre proceed. The quantities present are known to vary greatly with site and period of time after feeding so absolute amounts probably mean very little in terms of diet or site comparisons, even when calculated on a body-weight basis. The molar proportions of the VFA present, on the other hand, have been shown to vary only with site (Argenzio \& Southworth, 1975). These results have been expressed as molar proportions of VFA present in ileal digesta and faeces.

To aid the interpretation of TL and ADF results, the daily intake and the output at each site for a pig of $40 \mathrm{~kg}$ live weight (the mean weight of pigs in these studies) receiving $1.70 \mathrm{~kg}$ diet and 4.251 water/d have been calculated for each diet.

Statistical treatment of the results. This was as described by Sambrook (I979).

\section{RESULTS}

The aim of these studies was that, for each cannula site, digesta would be collected from six pigs given each of the three diets in successive I4-2I d periods. Not every animal completed the planned collections for reasons reported previously (Sambrook, 1979). The numbers of animals completing collections are given in the tables.

$T L$. The mean $24 \mathrm{~h} \mathrm{O:I} \mathrm{values} \mathrm{for} \mathrm{TL} \mathrm{are} \mathrm{shown} \mathrm{in} \mathrm{Table} 2$.

At the duodenum, the amount of TL passing the cannula exceeded intake for all three diets, but particularly for diet SSC. The only difference in O:I that was significant was that between diets BWF and SSC $(P<0.05)$. Further net secretion of TL occurred between the duodenum and mid-jejunum for diets BWF and SSG, while net absorption occurred for diet SSC. None of these changes was significant, nor was there any significant difference between the diets in $\mathrm{O}: \mathrm{I}$ at the mid-jejunum.

The net absorption of TL between the mid-jejunum and terminal ileum was significant $(P<0.00 I)$ for all three diets. The O:I value for diet SSC at the ileum was significantly lower $(P<0.01)$ than that for diet BWF; diet SSG was intermediate but not significantly 
Table 3. Mean 24 h output: intake for acid-detergent fibre in pigs given different diets (a) for digesta collection from pigs with intestinal re-entrant cannulas at one of three sites (b) for faeces collected from pigs without cannulas

(No. of pigs completing collections given in parentheses)

\begin{tabular}{lccc} 
Site of re-entrant & \multicolumn{2}{c}{ (a) Cannulated pigs } \\
cannula & Diet BWF† & Diet SSG & Diet SSC \\
Duodenum & $0.88(6)$ & $0.84(2)$ & $0.79(6)$ \\
Jejunum & $0.92(5)$ & $0.97(4)$ & $1 \cdot 00(4)$ \\
Ileum & $0.74(5)$ & $0.50(2)$ & $0.92(6)$
\end{tabular}

SE of difference between site means: least value 0.090 , greatest value 0.155 .

SE of difference between diet means: least value 0.052 , greatest value $0.15 \mathrm{I}$.

(b) Pigs without cannulas (six pigs/diet)

$\begin{array}{ccccc} & \text { Diet BWF } & \text { Diet BWF } & \text { Diet SSG } & \text { Diet SSC } \\ \text { Faeces } & 0.85 & 0.78 & 0.65 & 0.54\end{array}$

SE of difference between diet means: 0.048 .

$\mathrm{SE}$ of difference between means for faeces and ileum: least value 0.056 , greatest value 0.080 .

* For details of sites, see p. 279.

Diet BWF was finely milled (diet $\mathrm{BWF}_{1}$ ) when fed to pigs with ileal cannulas; for details of diets, see p. 279 and Table I.

Table 4. Daily intake, throughput at three sites in the small intestine and faecal output $(g)$ of total lipid $(T L)$ and acid-detergent fibre $(A D F)$, calculated for a pig of $40 \mathrm{~kg}$ live weight receiving $\mathrm{I} \cdot 70 \mathrm{~kg}$ meal and $4.25 \mathrm{l}$ water $/ d$

Diet BWF or $\mathrm{BWF}_{t}$

Diet SSG

Diet SSC

TL

Intake
Duodenum
Jejunum
Ileum
Faeces

69
83
101
$17^{*}$
29
$23^{*}$

ADF

Intake

Duodenum

Jejunum

Ileum

Faeces

$\begin{array}{cc}122 & 174 \\ 107 & 146 \\ 112 & 169 \\ 90^{*} & 87 \\ 104 \\ 95^{*} & 113 \\ \text { Pigs given diet BWF } & \end{array}$

$\begin{array}{rr}68 & 52 \\ 86 & 85 \\ 112 & 75 \\ 14 & 5 \\ 14 & 4\end{array}$

$174 \quad 52$

$146 \quad 4 \mathrm{I}$

$169 \quad 52$

$87 \quad 48$

11328

different from the other two diets. In the large intestine there was little or no further net absorption of TL from diets SSG and SSC, but for diet BWF, there was significant $(P<0.05)$ net secretion or synthesis of TL. Over-all net absorption of TL was significantly $(P<0.001)$ different for all diets, with the O:I ratios ranking in the order $\mathrm{BWF}>\mathrm{BWF}_{1}>\mathrm{SSG}>\mathrm{SSC}$.

The absolute amounts of TL calculated for a $40 \mathrm{~kg}$ pig are shown in Table 4 . Although the $O: I$ values for all three diets at the duodenum were different, absolute amounts of TL passing the duodenum in $24 \mathrm{~h}$ were very similar. The mean concentrations of TL in digesta and faeces are shown in Table 5. At the duodenum, the concentration of TL in the ingested diet plus water had been reduced by the addition of endogenous secretions. This dilution effect was not so marked for TL as it was for other dietary fractions since the endogenous secretions contained substantial amounts of lipid.

$A D F$. The mean $24 \mathrm{~h}$ O:I values for ADF are shown in Table 3. 
Table 5. Mean concentrations of total lipid $(T L)$ and acid-detergent fibre $(A D F)$ in digesta and faeces $(\mathrm{mg} / \mathrm{g})$ in $24 \mathrm{~h}$ in pigs given different diets

(Mean values with their standard errors; no. of pigs in parentheses)

Diet BWF or BWF,

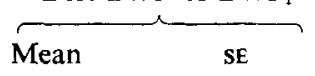

TL

Intake

Duodenum

Jejunum

Ileum

Faeces

$\mathrm{ADF}$

Intake

Duodenum

Jejunum

Ileum

Faeces

$$
\begin{array}{r}
\text { II.6 } \\
4 \cdot 8 \\
6 \cdot 2 \\
4 \cdot 3 \\
\left\{\begin{array}{l}
27 \cdot 6 \\
27 \cdot 4
\end{array}\right.
\end{array}
$$

20.5

6.2

6.9

$20 \cdot 8$

$\left\{\begin{array}{l}79 \cdot 4 \\ 91 \cdot 6\end{array}\right.$
0.39 (6)

$0.65(5)$

$0.50^{*}(5)$

$\mathrm{I} \cdot 42$ (6)

$\mathrm{I} \cdot \mathrm{I} 4^{*}(6)$

$0.42(6)$
$0.79(5)$
$0.85^{*}(5)$
$1.95(6)$
$2.90^{*}(6)$

Diet SSG

$\overbrace{\text { Mean }}^{\text {SE }}$

I I.4

$5 \cdot 9$

$8 \cdot 1$

$3 \cdot 2$

$27^{\circ} 9$

$29 \cdot 2$

10.3

$12 \cdot 0$

$21 \cdot 8$

$189 \cdot 5$

SE

$$
\begin{aligned}
& 0.30(2) \\
& 0.64(4) \\
& 0.07(2) \\
& 1.15(6)
\end{aligned}
$$

I. IO (2)

I.06 (4)

$6.15(2)$

$7.02(6)$

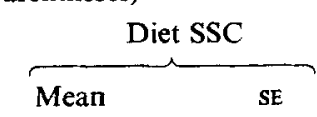

* Pigs given diet $B W F_{f}$.

Table 6. Mean values for daily flow of total volatile fatty acids $(\mathrm{mmol} / 24 \mathrm{~h})$ in (a) digesta from pigs with ileal cannulas and (b) faeces from pigs without cannulas (No. of pigs completing collections given in parentheses)

(a) Pigs with ileal cannulas

Diet $\mathrm{BWF}_{1}$
$78 \cdot 9 \pm \mathrm{I} 6 \cdot 6 \mathrm{I}(3)$

Diet BWF

$34 \cdot 9 \pm 4 \cdot 09(5)$
Diet SSG

$68 \cdot 7 \pm 4 \cdot 97(2)$

(b) Pigs without cannulas
Diet SSG

$24 \cdot 3 \pm 5 \cdot 81(6)$
Diet SSC

$18 \cdot 5 \pm 3 \cdot 28(4)$
Diet $\mathrm{BWF}_{\mathrm{t}}$

$26 \cdot 9 \pm 2 \cdot 07(6)$
Diet SSC

$3 \cdot 3 \pm 0.58(6)$

There had been apparent digestion of ADF anterior to the duodenal cannula for all three diets; values ranged from 0.12 for diet BWF to $0.2 \mathrm{I}$ for diet SSC although the differences between diets were not significant. At the mid-jejunum, however, the $\mathrm{O}: \mathrm{I}$ value was restored to 1.00 for diet SSC and 0.97 for diet SSG. The differences between the diets at the mid-jejunum were not significant. Between the mid-jejunum and terminal ileum there was digestion of ADF for all diets but this was only significant $(P<0.0 \mathrm{I})$ for diet SSG. There were significant differences $(P<0.05)$ between all diets at the terminal ileum with the diets ranking $\mathrm{SSC}>\mathrm{BWF}>\mathrm{SSG}$.

In the large intestine there was further significant $(P<0.00 \mathrm{I})$ digestion of ADF for diet SSC but a small net increase in ADF occurred for diets BWF and SSG. There was no significant difference between diets $B W F$ and $B W F_{i}$ in the over-all net digestion of ADF; the differences between the other diets were all significant $(P<0.05)$, with the diets ranking $\mathrm{BWF}=\mathrm{BWF}_{\mathrm{f}}>\mathrm{SSG}>\mathrm{SSC}$ in terms of O:I. The amounts of ADF calculated for a $40 \mathrm{~kg}$ pig are shown in Table 4.

The mean concentrations of ADF in digesta and faeces are shown in Table 5. The concentration of ADF ingested in diet plus water was reduced approximately threefold for each diet anterior to the duodenal cannula. Passage through the intestinal tract produced an increase in ADF concentration as other nutrients were more readily utilized than fibre. Faecal concentrations of ADF were four to six times higher than intake concentrations for diets BWF and SSG, and thirty times higher than intake concentration for diet SSC.

$V F A$. The mean values for the $24 \mathrm{~h}$ total flow of VFA in ileal digesta and faeces are 
Table 7. Mean $24 h$ volatile fatty acids (VFA) molar proportions for pigs given different diets (a) for digesta collected from pigs with ileal re-entrant cannulas and (b) for faeces collected from pigs without cannulas

(No. of pigs completing collections given in parentheses)

(a) Pigs with ileal cannulas

\begin{tabular}{|c|c|c|c|c|c|}
\hline & \multirow[b]{2}{*}{ Diet $\mathrm{BWF}_{\ell}$ (3) } & \multicolumn{2}{|c|}{ (a) Pigs with ileal cannulas } & \multicolumn{2}{|c|}{ SE of difference } \\
\hline & & Diet SSG (2) & Diet SSC (4) & Least value & Greatest value \\
\hline Acetate & $59 \cdot 9$ & $52 \cdot 2$ & $75 \cdot 5$ & 8.20 & $\begin{array}{l}11 \cdot 25 \\
-12 \cdot 88\end{array}$ \\
\hline $\begin{array}{l}\text { Proplonate } \\
\text { Butyrate }\end{array}$ & $\begin{array}{r}37^{-0} \\
0.4\end{array}$ & $\begin{array}{l}31 \cdot 2 \\
13 \cdot 0\end{array}$ & $\begin{array}{r}13.9 \\
7.4\end{array}$ & $\begin{array}{r}10 \cdot 11 \\
3.28\end{array}$ & $\begin{array}{r}13.88 \\
4.50\end{array}$ \\
\hline Other VFA & $2 \cdot I$ & 3.6 & $3 \cdot 2$ & 0.22 & 0.30 \\
\hline
\end{tabular}

(b) Pigs without cannulas

\begin{tabular}{|c|c|c|c|c|c|c|}
\hline & \multirow{3}{*}{$\begin{array}{c}\text { Diet BWF } \\
(5)\end{array}$} & \multicolumn{3}{|c|}{ 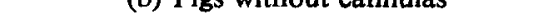 } & \multirow{2}{*}{\multicolumn{2}{|c|}{ SE of difference }} \\
\hline & & \multirow{2}{*}{$\begin{array}{l}\text { Diet BWF } \\
\text { (6) }\end{array}$} & \multirow{2}{*}{$\begin{array}{c}\text { Diet SSG } \\
\text { (6) }\end{array}$} & \multirow{2}{*}{$\begin{array}{l}\text { Diet SSC } \\
\text { (6) }\end{array}$} & & \\
\hline & & & & & Least value & Greatest value \\
\hline Acetate & $66 \cdot I$ & 65.4 & $69 \cdot 2$ & $63 \cdot I$ & $2 \cdot 79$ & $2 \cdot 97$ \\
\hline Propionate & $22 \cdot I$ & $20 \cdot 3$ & $14 \cdot 3$ & 18.1 & $1 \cdot 36$ & I. 45 \\
\hline Butyrate & 6.6 & 7.8 & $9 \cdot 3$ & 8.8 & I. 51 & 1.61 \\
\hline \multirow[t]{4}{*}{ Other VFA } & $5 \cdot 2$ & $6 \cdot 5$ & $7 \cdot 3$ & $10 \cdot 0$ & $1 \cdot 28$ & $1 \cdot 36$ \\
\hline & & & \multicolumn{4}{|c|}{ SE of difference between means for faeces and ileum } \\
\hline & & & \multicolumn{2}{|c|}{ Least value } & \multicolumn{2}{|c|}{ Greatest value } \\
\hline & $\begin{array}{l}\text { Acetate } \\
\text { Propionate } \\
\text { Butyrate } \\
\text { Other VFA }\end{array}$ & & & & & $\begin{array}{l}.65 \\
.46 \\
70 \\
73\end{array}$ \\
\hline
\end{tabular}

presented in Table 6. These results indicated that there were both dietary and site differences in total flow of VFA. The mean values for molar proportions of VFA in ileal digesta and faeces are shown in Table 7 .

Acetate was the predominant VFA constituting approximately $500-700 \mathrm{mmol} / \mathrm{mol}$ total VFA content for all diets and sites. Propionate was the second most predominant VFA and butyrate was usually third, with other VFA (caproate and valerate) generally comprising the smallest VFA fraction. At the ileum the proportion of other VFA was significantly lower $(P<0.05)$ for diet BWF, than for diets SSG and SSC; other differences between diets were not significant.

In the faeces there was no difference between the normal and finely-milled forms of diet BWF for any VFA; for the other diet comparisons there were some effects on all VFA except butyrate. Acetate was significantly higher $(P<0.05)$ for diet SSG than for diet SSC but was otherwise unaffected by diet. The molar proportion of propionate for diet SSG was significantly lower than for diets BWF and $\mathrm{BWF}_{t}(P<0.00 \mathrm{I})$ and for diet SSC $(P<0.05)$. Diet SSC was significantly lower $(P<0.05)$ than diet BWF; diet $\mathrm{BWF}_{1}$ was intermediate between the two and not significantly different from either. The molar proportion of other VFA for diet SSC was significantly higher $(P<0.05)$ than for the other diets.

Comparison of ileal digesta with faeces showed that for each diet, the molar proportions of two of the four VFA fractions were affected by passage through the large intestine. In the case of diet $\mathrm{BWF}_{1}$ propionate was significantly lower $(P<0.01)$ and other VFA higher $(P<0.05)$; for diet SSG acetate was increased $(P<0.05)$ and propionate decreased $(P<0.05)$; while for diet SSC acetate was lower $(P<0.05)$ and other VFA higher $(P<0.00 \mathrm{I})$ in the faeces than in the ileal digesta. 
For all three diets the molar proportions of butyrate were unaffected by transit through the large intestine.

\section{DISCUSSION}

$T L$. A striking feature of the digestion of TL in the anterior small intestine was the net addition of considerable amounts of endogenous TL to the gut contents. This lipid would have originated from bile secreted into the intestine, from mucosal cells sloughed off during the passage of digesta and from secretions through the intestinal mucosa. The net additions of TL calculated for the $40 \mathrm{~kg}$ pig were $\mathrm{I} 4 \mathrm{~g}$, I8 $\mathrm{g}$ and $33 \mathrm{~g}$ for diets BWF, SSG and SSC respectively. At the mid-jejunum, the net additions for diets BWF and SSG amounted to 32 and $44 \mathrm{~g}$ respectively. Although there had been net absorption of approximately $10 \mathrm{~g}$ from diet SSC, there was still a net surplus of $23 \mathrm{~g}$ over the TL intake for that diet. The fact that absorption of lipid can occur so rapidly in the small intestine, as indicated by diet SSC, may mean that the values for net addition of TL were considerable underestimates of actual endogenous lipid addition. The net amounts of endogenous TL added to the digesta in the anterior small intestine in this study compare to values of $25-85 \mathrm{~g} / \mathrm{d}$ for pigs of up to I00 $\mathrm{kg}$ live weight reported by Horszczaruk (I97 $\mathrm{I}, \boldsymbol{b}$ ).

Most of the net absorption of TL occurred between the mid-jejunum and terminal ileum. In the large intestine there was little or no net absorption of TL from diets SSG and SSC while there was net addition of TL amounting to 12 and $6 \mathrm{~g}$ for diets BWF and BWF respectively. This additional lipid may have originated not only from cells sloughed from the intestinal wall and from secretion through the mucosa, but also from the bacterial population of the large intestine, and may have masked further absorption of TL in the large intestine. This idea is supported by work by Mason \& Just (1976), who showed that oral administration of antibiotic to pigs reduced the faecal excretion of total fat.

The values for the net absorption of TL anterior to the terminal ileum for the diets containing maize oil in the present study were 0.80 and 0.90 for diets SSG and SSC respectively. These values agree with those of Cunningham et al. (1963) which ranged from 0.79 to 0.91 for pigs with ileal re-entrant cannulas given diets of dried skim milk with added maize oil. The corresponding value for the cereal diet BWF $_{t}$ of 0.75 net absorption anterior to the terminal ileum found in this study is much higher than that of 0.54 reported by Cunningham et al. (I963) and the range of $0.30-0.62$ reported by Horszczaruk (I97 I $a, b$ ). It has to be borne in mind, however, that the cereal diet used in the present study was finely ground before feeding to pigs with ileal re-entrant cannulas, and the results of the digestibility trial showed that this fine grinding produced a significantly higher $(P<0.001)$ over-all net absorption of TL.

The over-all net absorption values for TL of 0.80 and 0.93 for diets SSG and SSC respectively correspond to a value of 0.79 for a semi-purified diet containing maize oil found by Howard et al. (1965). For the cereal diet BWF the over-all net absorption of TL was 0.58 , much lower than the value of 0.82 found by Howard et al. (I965) but nearer to that of $0.47-0.50$ reported by Horszczaruk (I97I $a, b$ ).

$A D F$. A similar pattern of apparent digestion of ADF to that found for diet BWF in this study was reported for a cereal diet used by Horszczaruk (197 I $a, b$ ). Using pigs slaughtered $2.5-4.5 \mathrm{~h}$ after feeding he found that there was retention of crude fibre in the stomach ( $17 \%$ more than intake), and that the low crude fibre levels in the anterior small intestine (58-85\% of intake) were restored almost to the amount eaten by the end of the small intestine.

The digesta collection and return system used in the present study may have emphasized the retention of fibre in the stomach by affecting gastric emptying. Low \& Zebrowska (1977) showed that although the total quantity of digesta was unaffected, there was significantly 
less dry matter and $\mathrm{N}(P<0.00 \mathrm{I})$ collected from a duodenal re-entrant cannula connected to the sealed collection and return system used in this study, than when a system open to atmosphere was used. The idea is further supported by the recovery of approximately $100 \%$ of ingested ADF at the mid-jejunum where the cannula would not have such a pronounced effect on gastric emptying. Thus except perhaps for diet BWF, there appears to be no net digestion of ADF in the proximal small intestine.

At the terminal ileum, the differences between the diets in the net digestion of ADF may be attributable to the different types of fibre in the diets. Diet BWF contained only the natural fibre in the cereals, diet SSC contained only purified cellulose, while diet SSG contained some purified cellulose but mostly the natural fibre contributed by the groundnut meal. Van Soest (1973a) reported that whilst purified cellulose was eventually completely digested, its initial rate of digestion was slower than for intact forage fibre. Thus, at the terminal ileum, there was greater net digestion of ADF from diets BWF and SSG (0.26$0.50)$ than from diet SSC (0.08), but diet SSC had the highest over-all net digestion after passage through the large intestine $(0 \cdot 46)$.

The net increase in ADF in the large intestine requires further explanation. It is unlikely that the increase in this fraction was due to bacterial cell wall material since this would have been extracted by the ADF reagent (Low et al. 1978). The discrepancy probably arose from an underestimate of ileal ADF content, possibly because of an effect on ADF flow similar to that suggested for the duodenum.

The value for over-all net digestion of purified cellulose of 0.46 found in this study agrees closely with those of $0.40-0.50$ found by Poijärvi (1944) for purified wood celluloses. It is much higher than the values of 0.2 I for wood flock found by Forbes \& Hamilton (1952) and 0.05 for solka floc found by Cunningham et al. (1962). In these two cases, however, the level of cellulose in the diets was higher than in the present study but the absolute amounts of cellulose digested were similar.

$V F A$. Considerably lower levels of VFA were found in the faeces than in the ileal digesta, despite the large intestine being a region of major production of VFA. How much of the material that disappears during passage through the large intestine is utilized by intestinal flora and how much absorbed by the pig, and in which parts of the large intestine this happens, can not be determined in this study. Barcroft et al. (1944) and Elsden et al. (1946) have shown that substantial VFA absorption occurs from the caecum and colon (and lower levels of absorption from the stomach and small intestine) of the pig.

The contribution of the absorbed VFA to the pig's energy requirements has been estimated. Friend et al. (1964), by comparing carotid and portal blood, calculated that the possible contribution of absorbed acetic, propionic and butyric acids amounted to 5-10\% of digestible energy (DE) intake for a $30 \mathrm{~kg}$ pig. Farrell \& Johnson (1972) estimated that the VFA produced in the caecum of a $40 \mathrm{~kg}$ pig could supply $2-3 \%$ of DE intake. If the caecum contains approximately one-third of the VFA present in the large intestine of the pig (Friend et al. 1963) then these two estimates are in agreement that VFA produced in the large intestine of the pig could represent approximately $10 \%$ of the DE intake.

Since VFA are readily absorbed from the large intestine, the quantities present in the digesta and faeces mean very little in terms of quantities of fibre digested by the pig. The molar proportions of the main VFA present give an indication of the effect of diet and site upon organic acid production. In spite of some differences between diets in the molar proportions of particular VFA, the over-all pattern of acetate $>$ propionate $>$ butyrate in both ileal digesta and faeces was maintained. The proportion of butyrate was unaffected by site or diet, in agreement with work by Argenzio \& Southworth (I975). The molar proportions of acetate, propionate and butyrate present in faeces from diet BWF $(660,220$ and $70 \mathrm{mmol} / \mathrm{mol}$ respectively) are very similar to the mean values for the caecal contents of 
bran-fed pigs (620, 280 and $100 \mathrm{mmol} / \mathrm{mol}$ respectively) found by Elsden et al. (1946), and mean values for faeces from pigs fed barley-based diets of 689,220 and $60 \mathrm{mmol} / \mathrm{mol}$ respectively, found by Mason \& Just (1976).

The author wishes to thank Dr R. Braude for his advice and critical appraisal of the script, Dr H. L. Buttle for the surgical preparation of the animals, Mrs Rosemary Fulford for advice on statistical evaluation of the results, and Dr A. G. Low, Dr I. G. Partridge and $\mathrm{Mr}$ R. J. Pittman for assistance with digesta collections.

\section{REFERENCES}

Argenzio, R. A. \& Southworth, M. (1975). Am. J. Physiol. 228, 454.

Barber, R. S., Braude, R., Mitchell, K. G. \& Pittman, R. J. (1972). Anim. Prod. 14, 199.

Barcroft, J., McAnally, R. A. \& Phillipson, A. T. (1944). J. exp. Biol. 20, I 20.

Braude, R., Fulford, R. J. \& Low, A. G. (1976). Br. J. Nutr. 36, 497.

Cunningham, H. M., Friend, D. W. \& Nicholson, J. W. G. (1962). Can. J. Anim. Sci. 42, I 2.

Cunningham, H. M., Friend, D. W. \& Nicholson, J. W. G. (1963). Can. J. Anim. Sci. 43, 215.

Elsden, S. R., Hitchcock, M. W. S., Marshall, R. A. \& Phillipson, A. T. (I946). J. exp. Biol. 22, 191.

Farrell, D. J. \& Johnson, K. A. (1972). Anim. Prod. 14, 209.

Folch, J., Lees, M. \& Sloane-Stanley, G. H. (1957). J. biol. Chem. 226, 497.

Forbes, R. M. \& Hamilton, T. S. (1952). J. Anim. Sci. 11, 480.

Friend, D. W., Cunningham, H. M. \& Nicholson, J. W. G. (1963). Can. J. Anim. Sci. 43, 156.

Friend, D. W., Nicholson, J. W. G. \& Cunningham, H. M. (1964). Can. J. Anim. Sci. 44, 303.

Horszczaruk, F. (1971 a). Biul. Inst. Genet. Hodow. Zwierz. pol. Akad. Nauk, no. 21, p. Io1.

Horszczaruk, F. (1971 b). Biul. Inst. Genet. Hodow. Zwierz. pol. Akad. Nauk, no. 21 , p. 117.

Howard, A. N., Leat, W. M. F., Gresham, G. A., Bowyer, D. E. \& Dalton, E. R. (I965). Br. J. Nutr. 19, 383.

Low, A. G., Sambrook, I. E. \& Yoshimoto, J. T. (1978). 29th Ann. Mtg E.A.A.P. Stockholm.

Low, A. G. \& Zebrowska, T. (1977). Br. J. Nutr. 38, 145.

Mason, V. C. \& Just, A. (1976). Z. Tierphysiol. Tierernähr. Futtermittelk. 36, 301.

Poijärvi, I. (1944). Acta Agral. fenn. 57, 1.

Sambrook, I. E. (1979). Br. J. Nutr. 42, 267.

Van Soest, P. J. (1973a). Fedn Proc. Fedn Am. Socs exp. Biol. 32, 1804.

Van Soest, P. J. (1973b). J. Ass. off. Analyt. Chem. 56, 781 . 